\section{DISCUSSION}

Combined AVR with CABG and TAVI with PCI are current treatment options for aortic valve stenosis with concomitant CAD. Currently, treatment strategies are guided by operator preference and very limited data. At our institution, $\mathrm{PCI}$ is performed before TAVI in eligible patients with $\mathrm{CAD}$, followed by symptom reevaluation. It is evident however, that combined AVR with CABG and TAVI with PCI are less than ideal options for high-risk patients with complex multivessel CAD.

The success of the first hybrid surgical revascularization and TAVI with reduction of crossclamp and bypass times 3 years ago encouraged us to apply this technique in extremely high-risk patients. Optimizing the procedure resulted in an off-pump complete surgical revascularization with an aortic no touch technique combined with transaortic TAVI without aortic crossclamping and cardiopulmonary bypass in the most recent 2 cases. This procedure potentially provides an alternative treatment option for patients with prohibitively complex anatomy for a combined CABG and AVR.

Excision of calcified leaflets, as described in the first 3 cases, could potentially reduce paravalvular leakage and expand the indication for TAVI to aortic regurgitation without valvular calcification.

\section{CONCLUSIONS}

The described hybrid procedure, combining transaortic TAVI and off-pump CABG with the aortic no touch technique, shows promising outcomes and potentially provides an alternative to combined high-risk AVR and surgical revascularization. To our knowledge, this is the first successful implantation of a balloon-expandable transcatheter valve with native valve excision, potentially reducing paravalvular leakage and possibly expanding the indication for TAVI to aortic regurgitation without valvular calcification.

\section{References}

1. Langanay T, Flécher E, Fouquet O, Ruggieri VG, De La Tour BL, Félix C, et al. Aortic valve replacement in the elderly: the real life. Ann Thorac Surg. 2012;93: 70-7; discussion 77-8.

2. Dewey TM, Brown DL, Herbert MA, Culica D, Smith CR, Leon MB, et al. Effect of concomitant coronary artery disease on procedural and late outcomes of transcatheter aortic valve implantation. Ann Thorac Surg. 2010;89:758-67; discussion 767.

3. Nowicki ER, Birkmeyer NJ, Weintraub RW, Leavitt BJ, Sanders JH, Dacey LJ, et al. Multivariable prediction of in-hospital mortality associated with aortic and mitral valve surgery in Northern New England. Ann Thorac Surg. 2004;77: 1966-77.

4. Mandegar MH, Nazeri I, Abdi S, Roshanali F. Successful transcatheter aortic valve implantation through ascending aorta and total revascularization using Edwards SAPIEN Transcatheter Heart Valve System. Ann Thorac Surg. 2011;92:2262-3.

5. Santarpino G, Pfeiffer S, Fischlein T. Off-pump coronary artery bypass grafting in combination with transaortic transcatheter aortic valve implantation: a possible approach for patients with associated diseases. Int J Cardiol. 2012;157:e7-8.

\title{
Intraoperative transesophageal echocardiographic guidance for robotically assisted coronary sinus atrial septal defect repair
}

\author{
Linda Lau, MD, ${ }^{\text {a }}$ Kimberly Howard-Quijano, MD, ${ }^{a}$ Richard Shemin, MD, ${ }^{\mathrm{b}}$ and Aman Mahajan, MD, PhD, ${ }^{\mathrm{a}}$ \\ Los Angeles, Calif
}

Atrial septal defect (ASD) accounts for 10\% of congenital heart disease and $20 \%$ to $40 \%$ of cases presenting in adulthood. ${ }^{1}$ There are 4 categories: ostium secundum, ostium primum, sinus venosus, and coronary sinus defects. Coronary sinus defects, caused by incomplete formation of the

\footnotetext{
From the Departments of Anesthesiology ${ }^{\mathrm{a}}$ and Cardiothoracic Surgery, ${ }^{\mathrm{b}}$ the David Geffen School of Medicine, University of California, Los Angeles (UCLA), Los Angeles, Calif.

Disclosures: Authors have nothing to disclose with regard to commercial support.

Received for publication June 6, 2012; revisions received Aug 19, 2012; accepted for publication Sept 12, 2012; available ahead of print Oct 5, 2012.

Address for reprints: Kimberly Howard-Quijano, MD, Department of Anesthesiology, David Geffen School of Medicine at UCLA, 757 Westwood Plaza, Suite 3304, Los Angeles, CA 90095-7403 (E-mail: khquijano@mednet.ucla.edu). J Thorac Cardiovasc Surg 2013;145:602-4

$0022-5223 / \$ 36.00$

Copyright (c) 2013 by The American Association for Thoracic Surgery

http://dx.doi.org/10.1016/j.jtcvs.2012.09.014
}

atrioventricular folds, are the least common and are often associated with other congenital anomalies, including persistent left-sided superior vena cava (LSVC; Figure 1 ). ${ }^{2}$ Definitive treatment of a large coronary sinus defect is typically performed as an open surgical repair. We report the case of a patient with a coronary sinus defect in whom intraoperative transesophageal echocardiography (TEE) was instrumental in guiding robotically assisted surgical repair.

\section{CLINICAL SUMMARY}

A 40-year-old woman was seen with new-onset palpitations and shortness of breath. Preoperative transthoracic echocardiography and TEE demonstrated a $1.3-\mathrm{cm}$ primum ASD with a left-to-right shunt, dilated right ventricle, and pulmonary hypertension. Because of the defect's location, 


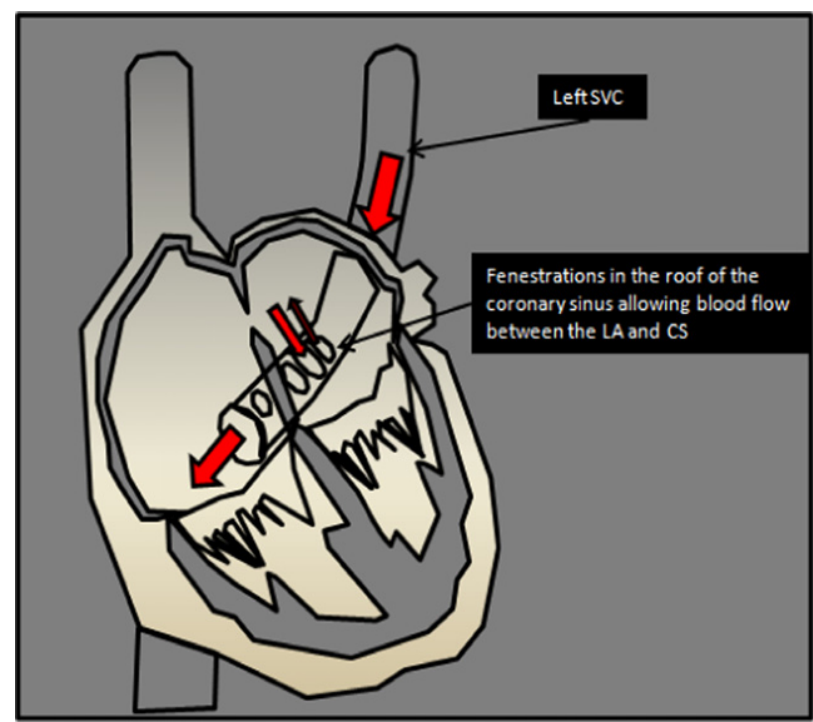

FIGURE 1. Schematic showing a coronary sinus $(C S)$ atrial septal defect. Arrows show bidirectional flow through the fenestrations between the left atrium $(L A)$ and coronary sinus. The blood from the left atrium and coronary sinus then enters the right atrium, leading to an interatrial shunt. $S V C$, Superior vena cava.

surgical intervention was planned rather than percutaneous closure. After induction of general anesthesia, a doublelumen endotracheal tube was placed. Intraoperative TEE revealed 2 defects differing from the preoperative diagnosis: a coronary sinus ASD and a patent foramen ovale (Figure 2). Agitated saline solution was injected into the left cephalic vein without evidence of any LSVC.

An outflow cannula was inserted percutaneously through the right internal jugular vein into the superior vena cava under echocardiographic guidance. The patient was placed in a modified left lateral decubitus position. The right femoral artery and vein were exposed, and a 5-cm right thoracotomy incision was performed in the fourth intercostal space. After systemic heparinization, the inflow and outflow cannulas were placed by the Seldinger technique under echocardiographic guidance in the femoral artery and vein, and cardiopulmonary bypass was initiated. A camera was placed in the thoracotomy incision, and robot ports were placed in the third and sixth intercostal spaces. The robot was positioned, and a transthoracic aortic crossclamp was placed. After cardiac arrest, both ASDs were repaired with a minimally invasive, robotically assisted approach. The robotic arms placed the sutures, while the surgical assistant followed the sutures and tied the knots. The patent foramen ovale was closed primarily with a polytetrafluoroethylene suture (Gore-Tex; W. L. Gore and Associates, Flagstaff, Ariz). The coronary sinus ASD was closed with a CorMatrix patch (CorMatrix Cardiovascular, Inc, Alpharetta, $\mathrm{Ga}$ ), and the coronary sinus was translocated into the left atrium by continuing the suture line around the lateral aspect of the coronary sinus. The patient was weaned from cardiopulmonary bypass, extubated on postoperative day 0 , and discharged home on postoperative day 4 .

\section{DISCUSSION}

We describe here a patient in whom intraoperative TEE correctly demonstrated the cardiac defect to be a coronary sinus ASD, with no associated LSVC. Isolated coronary sinus defects constitute fewer than $1 \%$ of ASDs. ${ }^{3}$ Detailed 2- and 3-dimensional anatomic description of the defect allowed proper execution of the surgical repair. To our knowledge, this is the first reported case of robotically assisted surgical repair of a coronary sinus defect.

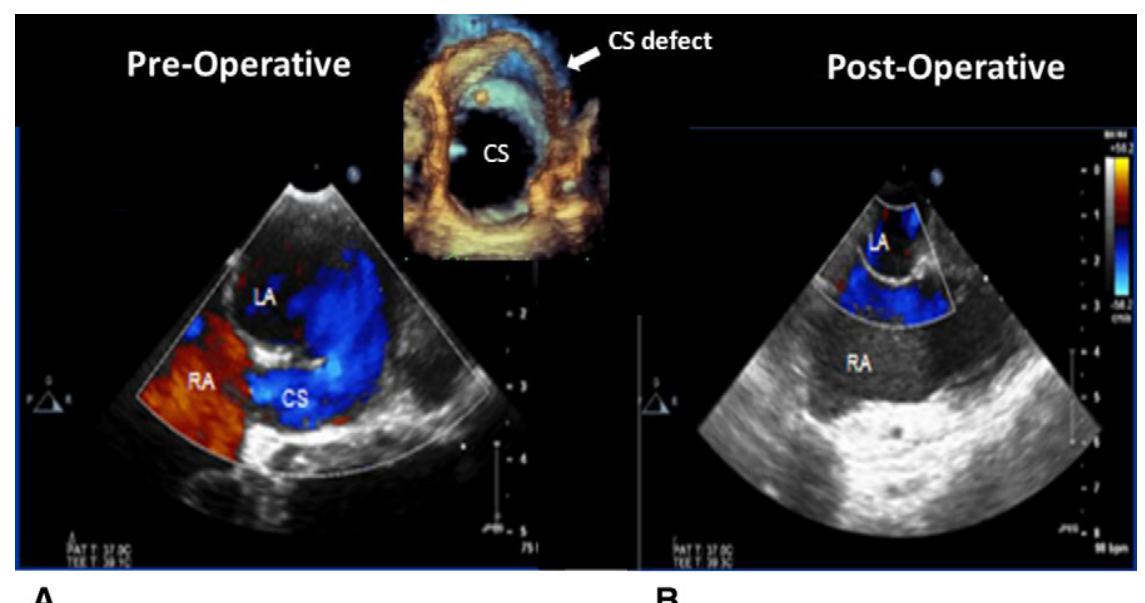

A

B

FIGURE 2. Midesophageal transesophageal echocardiographic images. A, Preoperative echocardiography. Lower panel is 2-dimensional image of coronary sinus $(C S)$ atrial septal defect demonstrating blood flow from left atrium $(L A)$ to the coronary sinus to the right atrium $(R A)$. $U p p e r$ panel is preoperative 3-dimensional image, en fosse view, demonstrating the large coronary sinus os $(C S)$ and the unroofed coronary sinus defect that is the origin of the interatrial communication. B, Postoperative 2-dimensional echocardiographic image after surgical repair demonstrating no residual atrial shunt. 
Coronary sinus ASDs are traditionally closed through a midline sternotomy with full surgical exposure and a 6- to 8-week recovery period. ${ }^{4}$ Recently, transcatheter device closures have been a less invasive alternative; however, not all ASDs are amenable to device closure. Minimally invasive robotically assisted repair offers a smaller incision then traditional midline sternotomy, with associated decreases in postoperative pain, wound infections, and length of recovery. After surgical repair, this patient had translocation of the coronary sinus to the left atrium, resulting in a small right-to-left shunt. Had the patient had a sizeable LSVC, this would have resulted in significant cyanosis, and the robotic approach would not have been appropriate in light of its limited surgical exposure. In the setting of an isolated coronary sinus ASD, however, this repair left a clinically insignificant shunt. At discharge, this patient had an oxygen saturation of $100 \%$ on room air.

Although echocardiography has been the mainstay for assessment of cardiac defects, preoperative transthoracic echocardiography and TEE failed to identify this anomaly correctly. It is probable that the large size of the coronary sinus os in the setting of an unroofed sinus created a mistaken preoperative diagnosis of a primum ASD. Intraoperative TEE, in contrast, provided precise understanding of the cardiac defects, including ruling out other associated anomalies such as LSVC that could have influenced surgical approach and outcome in a robotically assisted repair. Previous reports suggest that intraoperative TEE can modify preoperative diagnosis in a third of patients and alter the surgical plan in $11 \%$ of cases. ${ }^{5}$ With the increasing popularity and success of minimally invasive or robotically assisted surgical repairs, in which surgical exposure is limited, intraoperative TEE imaging takes on an increasingly important role in aiding real-time surgical decision making.

We would like to thank Allison Chavarria, MS, and Christian Eisenring, NP, for their contributions to manuscript preparation.

\section{References}

1. Bedford DE. The anatomical types of atrial septal defect. Their incidence and clinical diagnosis. Am J Cardiol. 1960;6:568-74.

2. Ootaki Y, Yamaguchi M, Yoshimura N, Oka S, Yoshida M, Hasegawa T. Unroofed coronary sinus syndrome: diagnosis, classification, and surgical treatment. J Thorac Cardiovasc Surg. 2003;126:1655-6.

3. Joffe DC, Rivo J, Oxorn DC. Coronary sinus atrial septal defect. Anesth Analg. 2008;107:1163-5.

4. Kikuchi Y, Ushijima T, Watanabe G, Ishikawa N, Takata M, Yamamoto Y. Totally endoscopic closure of an atrial septal defect using the da Vinci Surgical System: report of four cases. Surg Today. 2010;40:150-3.

5. Minhaj M, Patel K, Muzic D, Tung A, Jeevanandam V, Raman J, et al. The effect of routine intraoperative transesophageal echocardiography on surgical management. J Cardiothorac Vasc Anesth. 2007;21:800-4. 